\title{
Effect of Fuel Mass Distribution on Ethanol Combustion in Diesel Engine
}

\author{
S. Yamamoto, D. Sakaguchi, H. Ueki and M. Ishida \\ Graduate School of Engineering Nagasaki University \\ Nagasaki, Japan \\ shohei@tfl.mech.nagasaki-u.ac.jp
}

\begin{abstract}
A laser 2-focus velocimeter (L2F) has been applied for measurements of velocity and size of droplets in the dense region of diesel fuel spray under the atmospheric pressure condition. The fuel mass distribution in the spray obtained by the measurement was compared with the one simulated by using 3DCFD code KIVA-3V. The radial velocity of spray droplets near the injector nozzle in the KIVA-3V code was changed to reproduce the measured fuel mass distribution. The combustion simulations of tetradecane $\left(\mathrm{C}_{14} \mathrm{H}_{30}\right)$ and $\mathrm{Et20}$, which consists of $80 \%$ tetradecane and $20 \%$ ethanol by mass, were conducted by using both original and modified KIVA-3V codes. It was found that the simulation results of heat release rate and ignition delay period remained almost unchanged even though the mass distribution was changed. However, the predicted amount of soot formation simulated by using original KIVA-3V code was different from that simulated by using modified KIVA-3V code in both of tetradecane and Et20 combustion simulations.
\end{abstract}

Keywords- diesel spray; mass distribution; simulation; ethnol blend fuel;

\section{INTRODUCTION}

Reduction of carbon dioxide emission has been strongly required for suppression of global warming. Utilization of bioethanol as the fuel for diesel engines which has a high thermal efficiency is one of the effective measures for meeting the requirement, because bio-ethanol is a carbon neutral fuel. Thus, various study on using ethanol as diesel fuel have been conducted[1-6]. The diesel engine has the problem of exhaust emissions such as nitrogen oxides (NOx) and particulate matter (PM). Very low emission can be achieved by improving combustion and passing the exhaust gas through after treatment devices. However, extra fuel is required for activating the catalyst in after treatment devices. Therefore, it is necessary to achieve lower emission by further improvement of combustion. Spatial distribution of fuel vapor and air is non-uniform during diesel combustion. This is one of reasons to make it difficult to reduce PM and NOx simultaneously in the diesel combustion. Highly dispersed spray has been studied [7-8] for enhancing fuel-air mixing. It is difficult to obtain any information of spray droplets near the nozzle hole exit because droplets are highly concentrated. Thus, the effect of fuel mass distribution on combustion is unclear. In this study, a laser 2-focus velocimeter (L2F) [9] has been applied for measurements of spray droplets in order to clarify the mass distribution in the diesel spray. The L2F can measure the velocity and size of droplets simultaneously even in the dense region of diesel fuel spray, because the L2F has a micro scale probe. The fuel mass distribution obtained by the L2F measurements was compared with the result simulated by using a computer code named KIVA-3V[10-11] for 3D-CFD (3 dimensional Computational Fluid Dynamics). The radial velocity of spray droplets near the injector nozzle in the original KIVA-3V code was changed to reproduce the measured fuel mass distribution. Combustion simulations of tetradecane and Et20, which consists of $80 \%$ tetradecane and $20 \%$ ethanol by mass, were conducted by using the original and modified KIVA-3V codes. The effects of the mass distribution on combustion of tetradecane and Et20 are clarified by comparing the heat release rate, ignition delay period and the predicted amount of soot existing for the duration of combustion.

\section{EXPERIMENTAL SETUP}

The measurement probe of the L2F consists of highly concentrated two foci as shown in Fig. 1. The focus size $F=3$ $\mu \mathrm{m}$, the length of the focus $L=20 \mu \mathrm{m}$, and the distance between two foci $S=17 \mu \mathrm{m}$. The flight-time $t_{1}$ and the scattering-time $t_{2}$ were measured by the clock signal with a frequency of $480 \mathrm{MHz}$. The droplet velocity was calculated by

$$
u=S / t_{1}
$$

Based on the relation that the ratio of $t_{1}$ and $t_{2}$ corresponds to the ratio of $S$ and $(d p+F)$, the droplet size was estimated by

$$
d p=u^{*} t_{2}-F
$$

Fig. 2 shows the system of spray measurement by L2F. Diesel fuel (JIS\#2) was intermittently injected into the atmosphere by the common rail system. The rail pressure was set at $80 \mathrm{MPa}$. The injector nozzle diameter was $0.113 \mathrm{~mm}$. The distance $z$ from nozzle exit was taken in the direction of the spray axis, and the $x$-axis is perpendicular to a plane formed by the laser beam axis and spray axis. Measurements were conducted in the plane perpendicular to the $z$-axis; $z=9$ $\mathrm{mm}$, and the $\mathrm{x}$-coordinates of measurement positions are $x=$ $\pm 0.1, \pm 0.3, \pm 0.5, \pm 0.7, \pm 0.9, \pm 1.1, \pm 1.3$. The number of data measured by L2F was set 10,000 at each measurement position. 


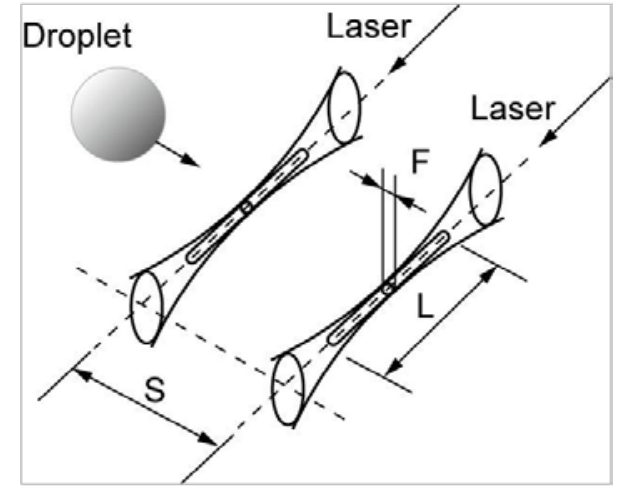

Figure 1. Measurement probe of L2F

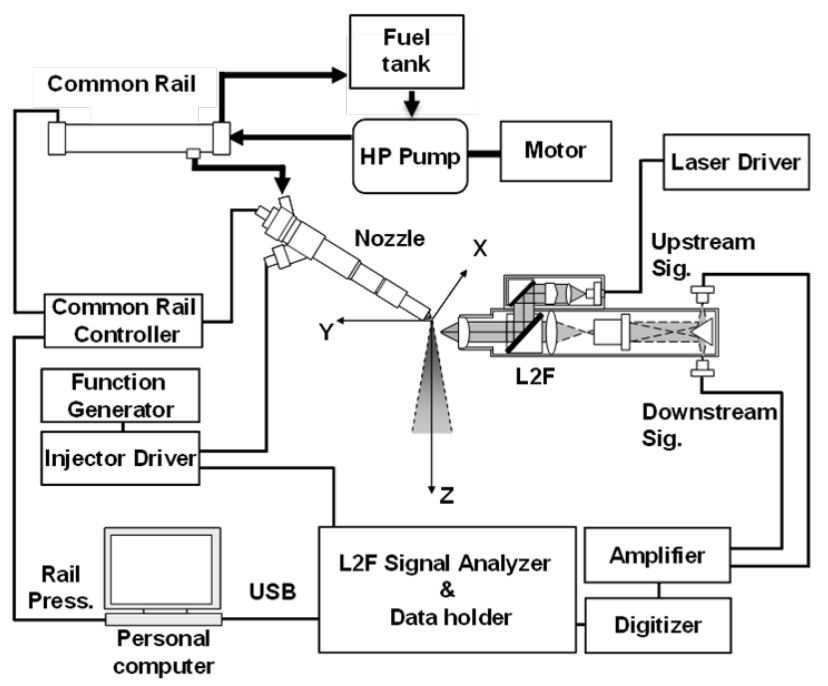

Figure 2. Fuel spray measurement system

\section{NUMERICAL SIMULATION}

3D-CFD code KIVA-3V used is a standard tool to simulate numerically the disintegration, collision, evaporation, and combustion of spray droplets on the condition of three dimensional, unsteady, and turbulent flow in the combustion chamber of the reciprocating engine.

The soot formation model of Hiroyasu[12] and the soot oxidation model of Nagle-Strickland-Constable[13] were adopted for predicting soot emission. These models were written in the Arrhenius single step form. The rate of change of soot mass during the period of combustion equals the soot formation rate minus the soot oxidation rate.

$$
d M_{\text {soot }} / d t=d M_{\text {form }} / d t-d M_{\text {oxid }} / d t
$$

The soot formation rate is given by

$$
d M_{\text {form }} / d t=A_{f} M_{f v} P^{0.5} \exp \left(-E_{f} /(R T)\right) .
$$

where $A_{f}=750, M_{f v}$ is the fuel vapor mass, $P$ is the pressure, and $E_{f}=12,500 \mathrm{cal} / \mathrm{mole}$. The soot oxidation rate is given by

$$
d M_{\text {oxid }} / d t=6 M_{w c} M_{s} R_{\text {Total }} /\left(\rho_{s} D_{s}\right)
$$

where $M_{w c}$ is the carbon molecular weight (12 g/mole), $\rho_{s}$ is the soot density $\left(2 \mathrm{~g} / \mathrm{cm}^{3}\right), D_{s}$ is the soot diameter $\left(3 \times 10^{-6} \mathrm{~cm}\right), M_{s}$ is the soot mass. $R_{\text {Total }}$ is the net reaction rate[14]. In the case of calculation for ethanol blend fuel, in order to represent low sooting nature of ethanol, Equation (4) is improved as follow;

$$
\begin{gathered}
d M_{\text {form }} / d t=K_{e f f} A_{f} M_{f v} P^{0.5} \exp \left(-E_{f} /(R T)\right) . \\
K_{\text {eff }}=T S I_{\text {mix }} / T S I_{\text {gasoil. }} .
\end{gathered}
$$

$$
T S I_{\text {mix }}=T S I_{\text {gasoil }} X_{\text {tet }}+T S I_{\text {ethanol }} X_{\text {ethanol }}
$$

where TSI is the Threshold Sooting Index proposed by Calcote and Manos[15]. TSI gasoil $=31.23$, TSI $I_{\text {ethanol }}=2.02[16] . T S I_{\text {mix }}$ is for the blend fuel. $X_{\text {tet }}$ and $X_{\text {ethanol }}$ are the molecular fraction of tetradecane and ethanol vapor included in each computational cell respectively.

Fig. 3 shows the grid used for the numerical simulations of processes from the disintegration to the combustion of spray droplets. The number of nodes was 30-60-100 in $r-\theta-z$ coordinates. Fuel was tetradecane $\left(\mathrm{C}_{14} \mathrm{H}_{30}\right)$ and ethanol $\left(\mathrm{C}_{2} \mathrm{H}_{5} \mathrm{OH}\right)$. The number of parcel was 10,000 . The Sauter mean size at the nozzle exit was set at the same as the nozzle hole diameter. The nozzle hole diameter was $0.113 \mathrm{~mm}$ in the case of the L2F measurement. The nozzle diameter was $0.29 \mathrm{~mm}$ in the case of combustion, because this size is practical for combustion of ethanol blend fuel in the diesel engine. The ambient pressure and temperature for the simulations of disintegration process were set at $0.1 \mathrm{MPa}$ and $300 \mathrm{~K}$ respectively. In the case of combustion simulation, the ambient pressure and temperature are $5.07 \mathrm{MPa}$ and $900 \mathrm{~K}$ respectively, and these are typical values at top dead center in the combustion chamber of a conventional diesel engine.

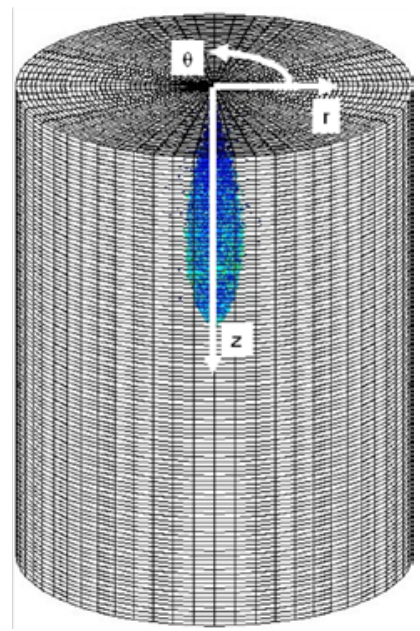

Figure 3. Computational grid 


\section{RESUlT AND DisCUSSION}

Fig. 4 shows the mass distribution in the plane; $z=9 \mathrm{~mm}$. Circles denote the result obtained by L2F measurements. The broken line denotes the result simulated by using the original KIVA-3V code and the solid line denotes the result simulated by using the KIVA-3V code modified to reproduce the mass distribution measured by the L2F. In the modified KIVA-3V code, the injection velocity in the direction perpendicular to spray axis was changed. The original KIVA-3V code overestimated the mass at spray axis. The mass distribution simulated by using modified KIVA-3V code corresponds well with the mass distribution by the L2F measurement. Then, the combustion simulations of tetradecane and Et20 were conducted by using both original and modified KIVA-3V codes. Fig. 5 shows simulation results of heat release rate $d Q / d t$. The broken and solid lines denote results simulated by using the original and the modified code respectively, and black line and gray line denote tetradecane and Et20 respectively. The ignition delay period and heat release rate by the original code are almost the same as these by the modified code even though the mass distribution is changed.

Fig. 6 shows the soot mass existing in the duration of combustion. The black solid and broken lines denote the simulation results of tetradecane combustion and the gray solid and broken ones denote the simulation results of Et20 combustion. In the case of Et20 combustion, the time when soot began to appear was later and the maximum value of the soot mass was smaller. These differences happened by blending fuel with ethanol is attributed to the promotion of premixing fuel and air due to longer ignition delay and the low sooting nature of ethanol. It should be also noticed that the maximum values of the soot mass simulated by using modified KIVA-3V code were smaller than these simulated by using original KIVA-3V code in both tetradecane and Et20 combustion. These may be attributed to decrease in fuel with high equivalence ratio due to change in internal structure of spray. In the following part of this paper, the change of equivalence ratio over time and the spatial distribution of equivalence ratio were investigated in detail.

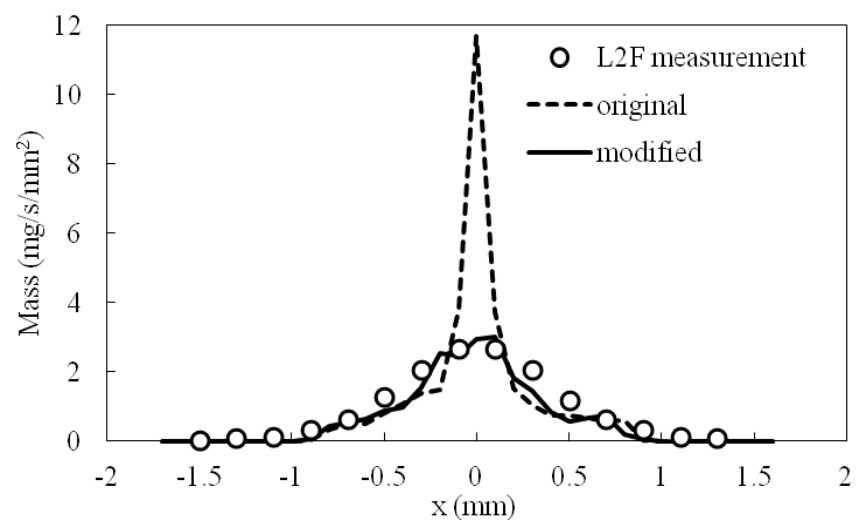

Figure 4. Fuel mass distributions

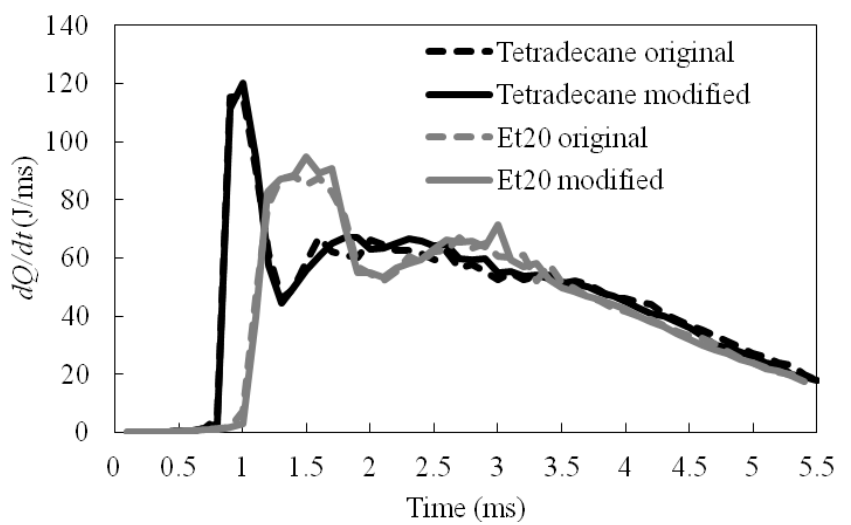

Figure 5. Heat release rate

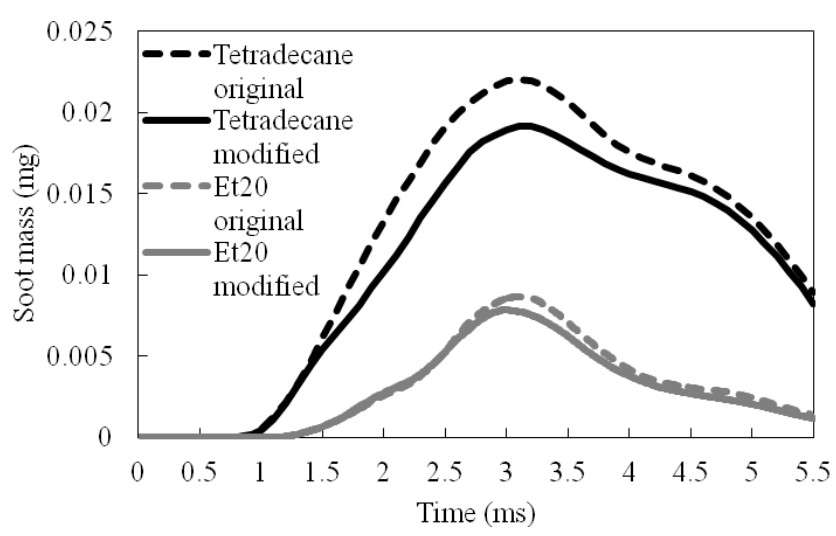

Figure 6. Time history of soot existing during combustion

Figs. 7, 8 and 9 show the relation between the exhaust emissions formed by the fuel combustion and the combustion conditions. The exhaust emissions, the amounts of soot and NOx formed, are drawn as contours in the plane of the equivalence ratio $\phi$ and the temperature $T$ ( $\phi-T$ map [17]). It is understood by this $\phi$ - T map, that the soot is formed under the temperature range between 1400 and $2200 \mathrm{~K}$ and the equivalence ratio higher than 2.5. It is also understood that the amount of NOx is large under the temperature higher than 2200 $\mathrm{K}$ and the equivalence ratio lower than 1 . Circles in Figs. 7, 8 and 9 show the correlation between the equivalence ratio $\phi$ and temperature $T$ of each computational cell for the case of Et20 at 1.2, 1.6 and $2.0 \mathrm{~ms}$ after the start of injection respectively. The number of circles exiting in soot formation region on the $\phi$ $-T$ map increased over time (i.e. the amount of soot formation increased). Fig. 10 shows the change in fuel quantity existing in the entire soot formation region with the time elapsed from the start of injection. The entire soot formation region is defined by the region of $\phi>2.5,1400<T<2200 \mathrm{~K}$ in the $\phi-T$ map. As shown in Fig. 10, the fuel quantity existing in the entire soot region of the Et20 case is smaller than that of the tetradecane case. In the case of tetradecane combustion, the fuel quantity existing in the entire soot formation region changed significantly when the mass distribution was changed. On the other hand, Et20 did not so. 


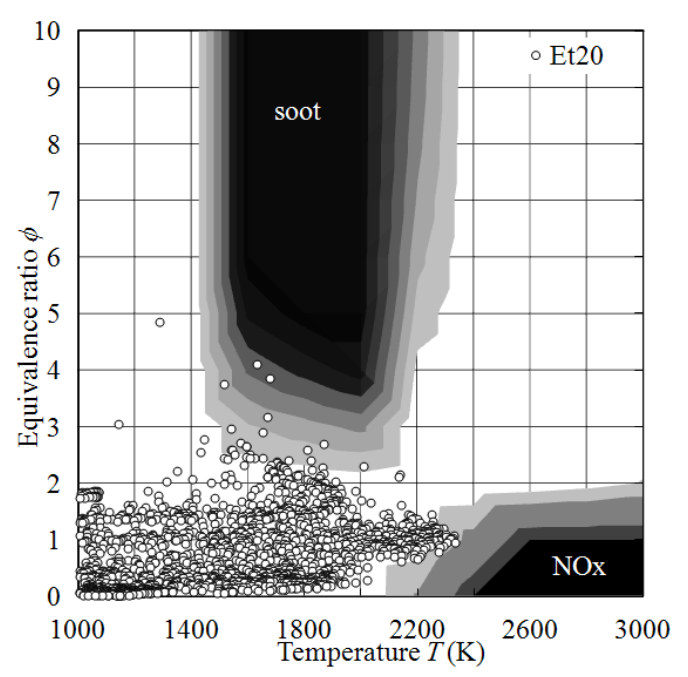

Figure 7. $\phi$ - T map (Et20, 1.2ms after start of injection)

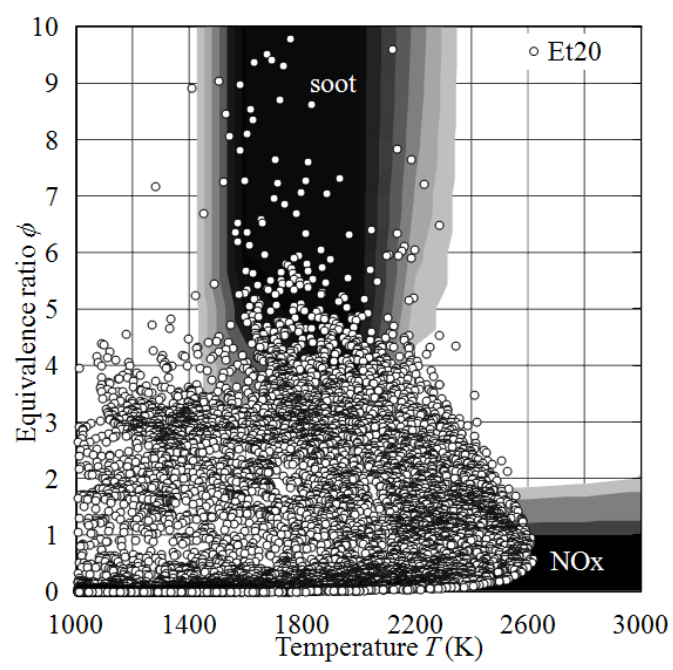

Figure 8. $\phi$ - T map (Et20, 1.6ms after start of injection)

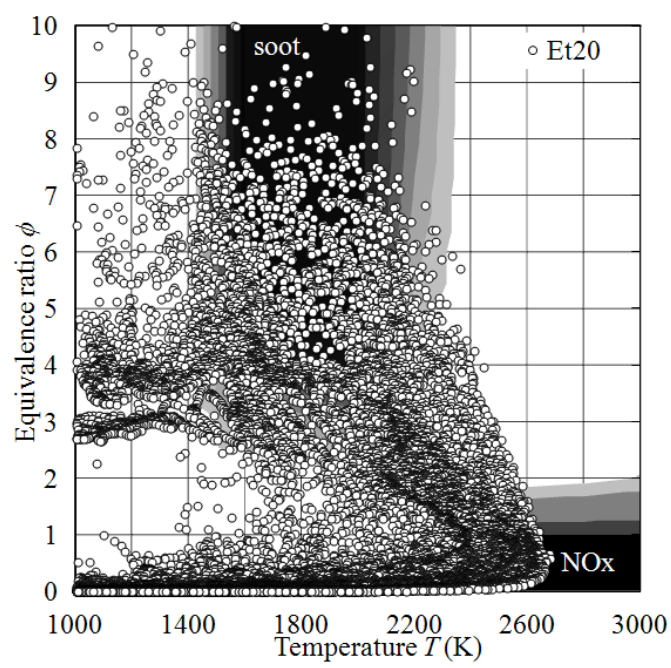

Figure 9. $\phi$ - T map (Et20, 2.0ms after start of injection)

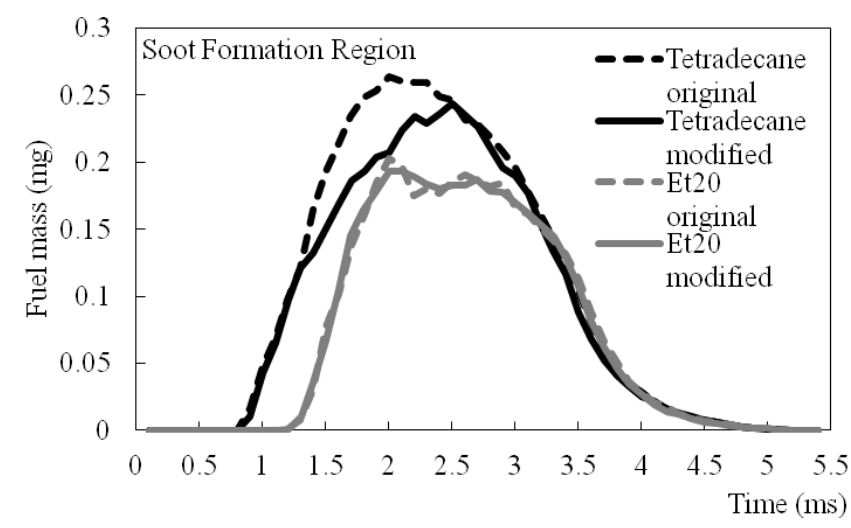

Figure 10. Fuel quantity existing at soot formation region

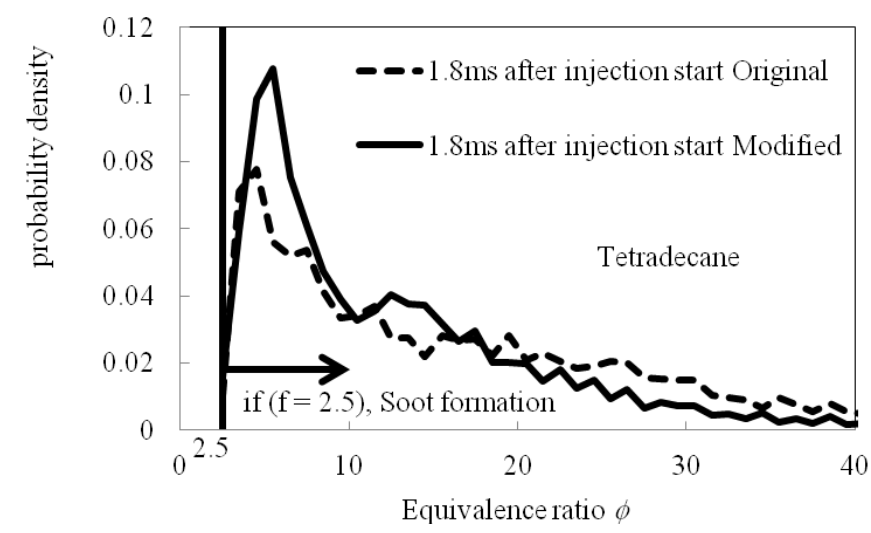

Figure 11. Probability density of equivalence ratio of fuel existing at soot formation region (1.8ms, Tetradecane)

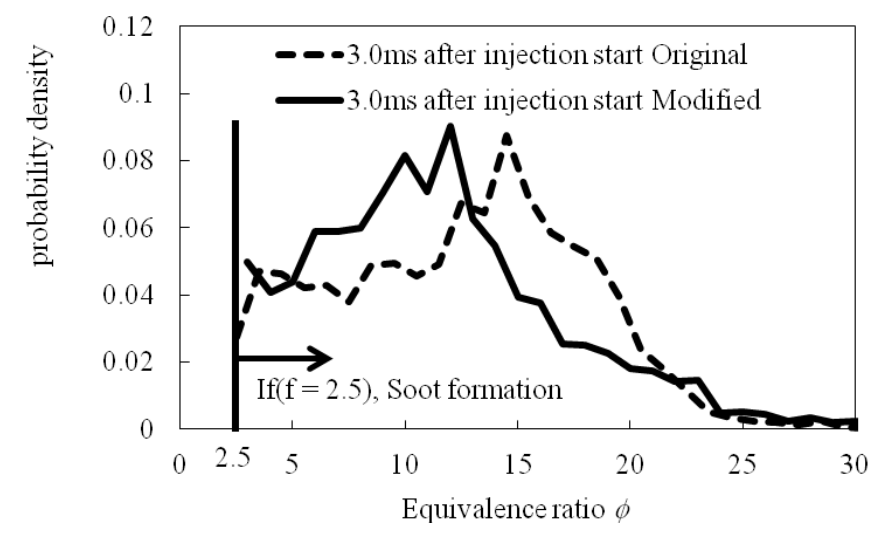

Figure 12. Probability density of equivalence ratio of fuel existing soot formation region (3.0ms, Et20)

The higher ratio of fuel with high equivalence ratio is, the more soot may be formed even though the fuel quantity existing in the entire soot formation region is almost the same. Fig. 11 and 12 show the probability density distributions of equivalence ratio $\phi$ of tetradecane and Et20 existing in the entire soot formation region respectively. These are distributions at the time when differences between the soot 


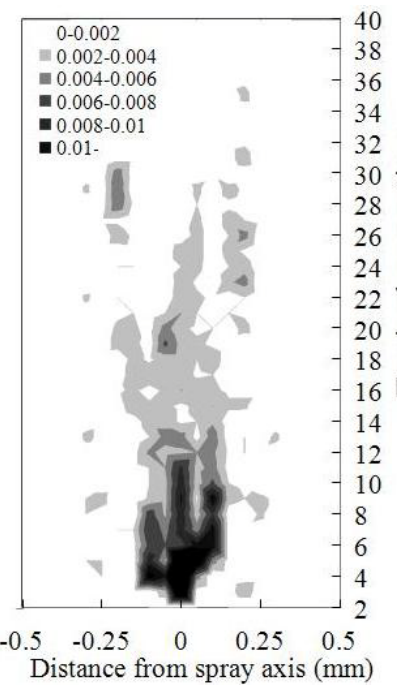

(a) Original code

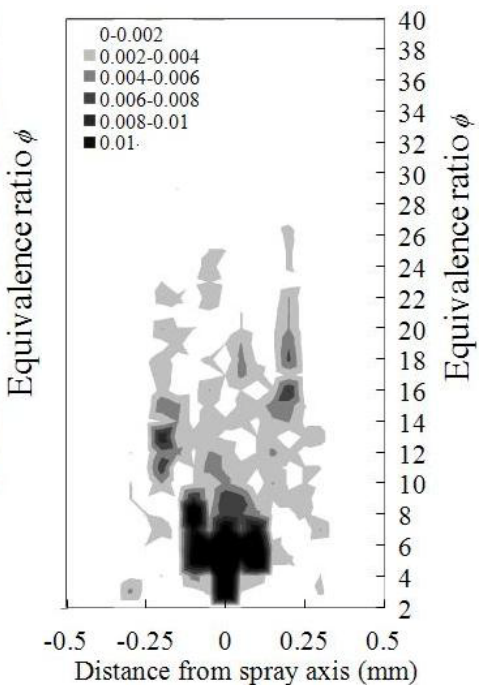

(b) Modified code
Figure 13. Correlation between equivalence ratio $\phi$ and distance from spray axis (1.8ms after start of injection, Tetradecane)

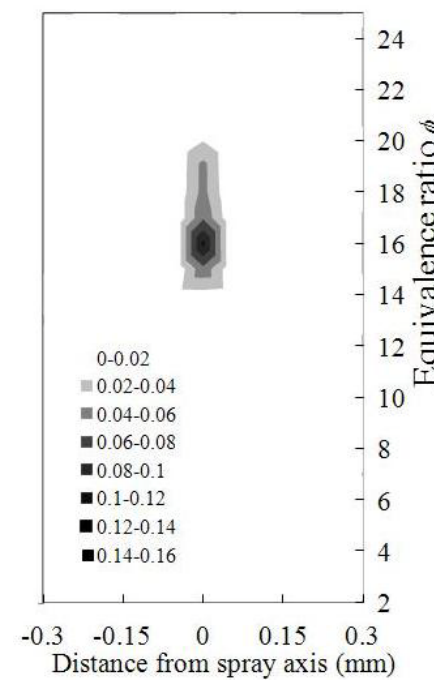

(a) Original code

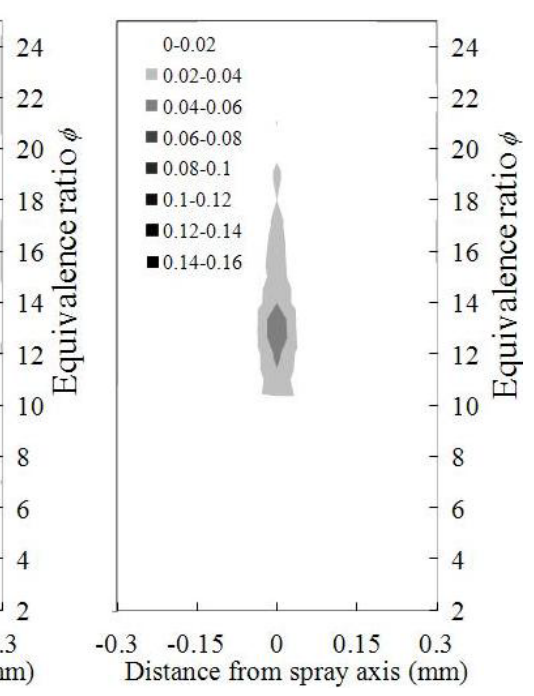

(b) Modified code
Figure 14. Correlation between equivalence ratio $\phi$ and distance from spray axis (3.0ms after start of injection, Et20)

mass simulated by using original KIVA-3V code and that simulated by using modified KIVA-3V code have begun to occur (1.8ms after stat of injection for tetradecane, $3.0 \mathrm{~ms}$ for Et20). As shown fig. 11, in the case of tetradecane combustion, the probability density of equivalence ratio simulated by using original code was larger than that simulated by using modified code above the equivalence ratio of 18 . On the other hand, as shown fig. 12, in the case of Et20 combustion, the probability density of equivalence ratio simulated by using original code was much larger than that simulated by using modified code in the equivalence ratio range between 14 and 20. As mentioned above, in the case of using original code, the probability densities of the equivalence ratio of fuel existing in the entire soot formation region on the $\phi$ - T map were higher in both tetradecane and Et20. Thus, the amount of soot mass simulated by using original code was larger in both fuels.

Figs. 13(a) and (b) show the correlations between equivalence ratio $\phi$ in each computational cell and its distance from spray axis in tetradecane combustion. The correlations in (a) and (b) were results simulated by using original and modified codes respectively. These figures show states at $1.8 \mathrm{~ms}$ after the start of injection. In the case of using original code, computational cells with the equivalence ratio above 18 were concentrated near the spray axis. On the other hand, in the case of using modified code, fuel was highly dispersed and there were smaller cells with equivalence ratio above 18 near the spray axis. Figs. 14(a) and (b) show the correlations between equivalence ratio $\phi$ in each cells and its distance from spray axis in Et20 combustion. The correlations of (a) and (b) were results simulated by using original and modified codes respectively. These figures show states at $3.0 \mathrm{~ms}$ after the start of injection. In the case of using original code, cells with equivalence ratio in the range between 14 and 20 were concentrated near the spray axis. On the other hand, in the case of using modified code, cells with high equivalence ratio exist near the spray axis. However, the peak of equivalence ratio was changed from 16 in the case of using original code to 12.

\section{CONCLUSIONS}

A laser 2-focus velocimeter (L2F) has been applied for measurements of velocity and size of droplets in the dense region of diesel spray and the spatial mass distribution in the plane; $z=9 \mathrm{~mm}$ from nozzle tip was investigated. Numerical simulation of atomization process was conducted by using the 3D-CFD code KIVA-3V. The simulation result was compared with the mass distribution measured by the L2F, and KIVA-3V code was modified to reproduce the L2F measurement results. Tetradecane and Et20, which consists of $80 \%$ tetradecane and $20 \%$ ethanol, were used as the fuels for combustion simulations. The effects of mass distribution on combustion of both fuels were investigated in detail. The concluding remarks are as follows;

(1) Comparing the mass distribution simulated by using original KIVA-3V code with that obtained by L2F measurement, the mass at spray axis was considerably overestimated.

(2) The simulation results of heat release rate and ignition delay by the original code were almost the same as these by the modified code even though the mass distribution was changed. However, the amount of soot mass existing for the duration of combustion simulated by using original KIVA-3V code was different from that simulated by using modified KIVA-3V code in both of tetradecane and Et20 (80\% tetradecane and 20\% ethanol blend fuel) combustion simulations.

(3) In the case of using modified KIVA-3V code, the amount of soot mass existing in the duration of combustion decreases in comparing the case of using original KIVA-3V code because computational cells with high equivalence ratio are reduced by dispersing fuel mass in both tetradecane and Et20 combustion. 


\section{ACKNOWLEDGMENT}

The authors would like to their gratitude for Mr. Takuya Shirakawa and the colleagues in Energy System Laboratory, Nagasaki University for securing experimental data.

\section{REFERENCES}

[1] K. Miwa, T. Wakabayashi, T. Ohsawa and M. Ikegami, "Combustion and performance of a diesel engine fueled with ethanol-gasoil blends", Proceedings of 8th International Symposium on Alcohol Fuels, pp. 595600, 1988.

[2] K. Ekholm, M. Karlsson, P. Tunestal, R. Johansson, B. Johansson and P. Strandh, "Ethanol-Diesel Fumigation in a Multi-Cylinder Engine", SAE paper No. 2008-01-0033, 2008.

[3] T. Shudo, T. Nakajima and K. Hiraga, "Simultaneous reduction in cloud point, smoke, and NOx emissions by blending bioethanol into biodiesel fuels and exhaust gas recirculation”, International Journal of Engine Research 10(1), pp. 15-26, 2009.

[4] M. Ishida, S. Yamamoto, H. Ueki and D. Sagaguchi, "Remarkable improvement of NOxePM trade-off in a diesel engine by means of bioethanol and EGR”, Energy 35 , pp. 4572-4581, 2010.

[5] D. B. Hulwan and S. V. Joshi, "Performance, emission and combustion characteristic of a multicylinder DI diesel engine running on dieselethanol-biodiesel blends of high ethanol content”, Applied Energy 88, pp. 5042-5055, 2011.

[6] S. H. Park, J. Cha, H. J. Kim and C. S. Lee, "Effect of early injection strategy on spray atomization and emission reduction characteristics in bioethanol blended diesel fueled engine”, Energy 39 , pp. 375-387, 2012.

[7] J. D. Naber and D. L. Siebers, ”Effects of Gas Density and Vaporization on Penetration and Dispersion of Diesel Sprays," SAE Paper No.960034, 1996.

[8] N. Tamaki, Y. Ishida and A. Higashi, "Practical Study on HighDispersion Atomization Enhancement Nozzle (Effects of Ambient Pressures on Atomization of Spray and Application to Actual Diesel Nozzle)”, Proceedings of ICLASS 2006, Paper ID ICLASS06-011, 2006.

[9] H. Ueki, M. Ishida, D. Sakaguchi, "Investigation of Droplet Disintegration in Diesel Spray Core by Advanced Laser 2-Focus Velocimeter," SAE Paper No.2005-01-1238, 2005.

[10] A. A. Amsden, Los Alamos Report, LA-12503-MS, 1993.

[11] A. A. Amsden, Los Alamos National Laboratory report, LA-13313-MS, 1997.

[12] H. Hiroyasu and K. Nishida, " Simplified three-dimensional modeling of mixture formation and combustion in a D.I. diesel engine”, SAE Paper No. 890269, 1989.

[13] J. Nagle and R. F. Strickland-Constable, "Oxidation of carbon between 1000-2000 C”, Proceedings of 5th Carbon Conference, Vol. I, pp. 154, Pergamon Press, Oxford, 1962.

[14] A. Sabau and E. Oanta, "Soot Modeling in Diesel Engine”, Proceedings of the 3rd International Conference on Environmental and Geological Science and Engineering, pp. 126-131, 2010.

[15] H.F. Calcote, D.F. Manos, "Effect of molecular structure on incipient soot formation”, Combustion and Flame 49 (1983) 289-304.

[16] Y. Yang, A. L. Boehman, R. J. Santro, "A study of jet fuel sooting tendency using the threshold sooting index (TSI) model”, Combustion and Flame 149, pp. 191-205, 2007.

[17] T. Kmimoto and M. Bae, "High Combustion Temperature for the Reduction of Particulate in Diesel Engines", SAE paper 880423, 1988. 